\title{
DEVELOPMENT OF SQUEEZING CYLINDER FOR INDIGENIZED MULTIPURPOSE TAMPING MACHINE
}

\author{
SHRUTI SINGH $^{1} \&$ S.S. BANWAIT ${ }^{2}$ \\ ${ }^{I}$ Student, Department of Mechanical Engineering, National Institute of Technical Teachers Training and \\ Research, Chandigarh, India \\ ${ }^{2}$ Professor, Department of Mechanical Engineering, National Institute of Technical Teachers Training and \\ Research, Chandigarh, India
}

\begin{abstract}
Squeezing Cylinder is an important part of Indigenized Multipurpose Tamping Machine. Indian Railways has been developing indigenized track tamping machines lately and the latest one being developed is indigenized multipurpose tamping machine. Analysis of failures in tamping unit shows that squeezing cylinder has major proportion in all reported failures. The present work addresses the problem of enhancing the life of squeezing cylinder by proposing En19 steel as new material. A squeezing cylinder is designed using Solid Works software and stress analysis is performed on ANSYS software using both the present material being used and the proposed materials i.e. En19 steel and a comparative study is then performed. The results show that the squeezing cylinder made of En19 steel gives better performance.

KEYWORDS: Squeezing Cylinder; Indigenized Multipurpose Tamping Machine; Solid Works; ANSYS \& En19 Steel
\end{abstract}

Received: Jun 09, 2020; Accepted: Jun 29, 2020; Published: Jul 25, 2020; Paper Id.: IJMPERDJUN2020456

\section{INTRODUCTION}

For quite a long time, Indian Railways is carrying out the task of routine maintenance of track with the help of huge on-track machines. Machine assisted tamping of railway track is a consistent activity in order to keep the track parameters within acceptable limits. M/s. Plasser \& Theurer has been the main supplier of tamping machines to Indian Railways. Table No. 1 gives a clear description of indicative cost at which these machines are supplied to Indian Railways.

Table 1: Indicative Cost of Machines (2015)

\begin{tabular}{|c|c|c|}
\hline S.NO. & Machine Type & Indicative Cost ( Rs. Cr.) \\
\hline 1 & $09-3 \mathrm{X}$ & 27.32 \\
\hline 2 & CSM & 20.07 \\
\hline 3 & DUO/WST & 7.00 \\
\hline 4 & UNIMAT-4S & 27.28 \\
\hline 5 & MPT & 6.93 \\
\hline 6 & DTS & 9.85 \\
\hline
\end{tabular}

To avoid the problem of long procurement time, high cost and large idle period of track maintenance machines sourced from outside, Indian Railways have started developing indigenized tamping machines. Following 
table shows the list of various indigenized track maintenance machines which Indian Railways posses.

Table 2: List of Machines

\begin{tabular}{|c|l|}
\hline S.No. & \multicolumn{1}{|c|}{ Name of Machines } \\
\hline 1. & Ballast Cleaning Machine (BCM) \\
\hline 2. & Ballast Regulating Machine (BRM) \\
\hline 3. & Continuous Tamping Machine (CSM) \\
\hline 4. & Tamping Machine-DUOMATIC (DUO) \\
\hline 5. & Shoulder Ballast Cleaning Machine (SBCM) \\
\hline 6. & Tamping Express (09-3X) \\
\hline 7. & Track Relaying Train (TRT) \\
\hline 8. & Point and Crossing Tamping Machine (UNIMAT) \\
\hline 9. & DGS Machine \\
\hline
\end{tabular}

\section{PROBLEM IDENTIFICATION}

$\mathrm{CPOH}$ Workshop Prayagraj has been involved in development and maintenance of various types of indigenized tamping machines. They have done a post $\mathrm{POH}$ analysis and reported that failure analysis of tamping units from 1.04.2018 to 31.12.2018 shows that squeezing cylinder have major proportion (51\%) in all reported failures. Table 3 show the different categories of failures encountered in tamping machine. It has been found that life of tamping unit can only be enhanced by improving the quality of squeezing cylinder.

Internal leakage in squeezing cylinder is due to excessive vibration and metallurgy of the cylinder body i.e. mild steel material. Though it is close die forging but toughness of material and material wear resistance can be enhanced by using some high carbon steel in place of mild steel.

There are two objectives of the present work. The first objective is to develop a CAD model of squeezing cylinder for indigenized multipurpose tamping machine and the second objective is to present a detailed comparative stress analysis between previous material IS2062 mild steel and new proposed material En19 steel.

Table 3: Failure Analysis

\begin{tabular}{|l|l|l|}
\hline S. No. & \multicolumn{1}{|c|}{ Catagory } & \multicolumn{1}{c|}{ Nature of Failure } \\
\hline 1 & Cat-A & Failures of Squeezing Cylinders \\
\hline 2 & Cat-B & Failure of Bearings \\
\hline 3 & Cat-C & failure of Tamping arms \\
\hline 4 & Cat-D & Failure of Vibration shaft \\
\hline 5 & Cat-E & Failure of Plate guard \\
\hline 6 & Cat-F & Failure of Hoses \\
\hline 7 & Cat-G & Play over Centre arm bush \\
\hline 8 & Cat-H & Other Failure \\
\hline
\end{tabular}




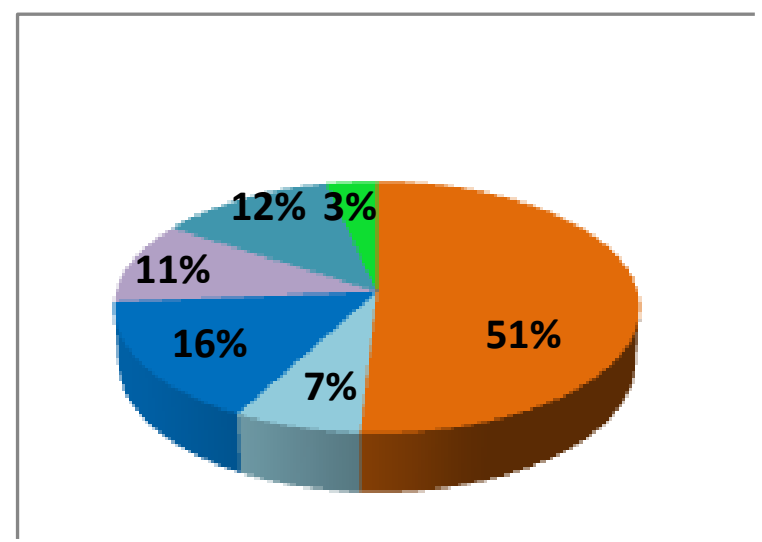

Figure1: Classification of Failures.

\section{MODELING AND ANALYSIS OF SQUEEZING CYLINDER}

Squeezing cylinder is an important part of indigenized multipurpose tamping machine. It is responsible to transfer the squeezing force from hydraulic fluid to tamping arms which further gets transferred to tamping tines and thus squeezing of ballast takes place.

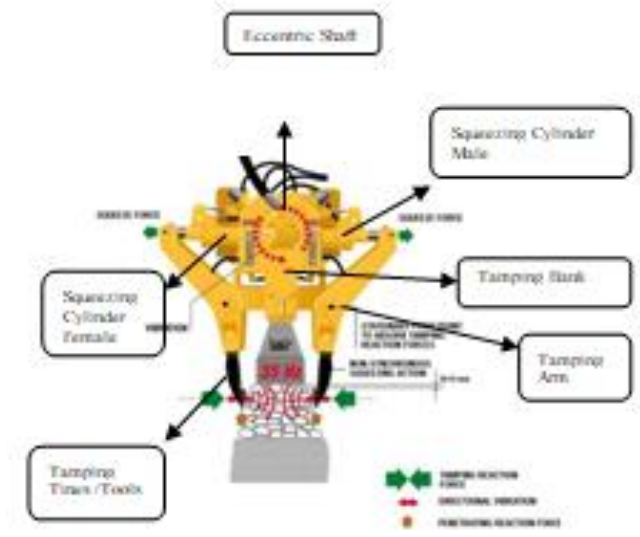

Figure 2: Multipurpose Tamping Machine.

In indigenized multipurpose tamping machine there are two squeezing cylinders squeezing cylinder female and squeezing cylinder male. These are connected to the eccentric shaft that provides vibratory motion to the tamping tines necessary for ballast packing. The CAD model of female squeezing cylinder is shown in figure 3 below:
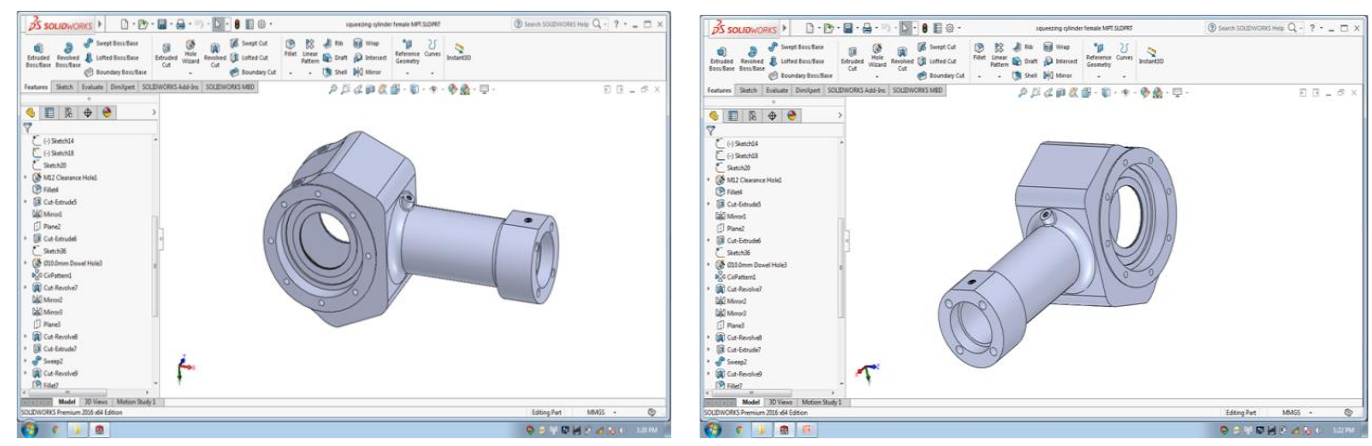

Figure 3: CAD Model of Squeezing Cylinder Female. 
Presently the squeezing cylinders were made of IS2062 mild steel, the composition and mechanical properties of which are listed in the table 4 and 5 respectively.

Table 4: Chemical Composition of IS2062 Mild Steel

\begin{tabular}{|c|c|}
\hline Chemical & Composite (Weight \%) \\
\hline $\mathrm{C}$ & 0.22 \\
\hline $\mathrm{Mn}$ & 1.50 \\
\hline $\mathrm{S}$ & 0.045 \\
\hline $\mathrm{P}$ & 0.045 \\
\hline $\mathrm{Si}$ & 0.040 \\
\hline
\end{tabular}

Table 5: Mechanical Properties of IS2062 Mild Steel

\begin{tabular}{|c|c|c|c|c|}
\hline Density & Tensile Strength Ultimate & Tensile Strength Yield & Modulus of Elasticity & Poisson's Ratio \\
\hline $7.85 \mathrm{~g} / \mathrm{cm}^{3}$ & $410 \mathrm{MPa}$ & $250 \mathrm{MPa}$ & $200 \mathrm{GPa}$ & 0.26 \\
\hline
\end{tabular}

With the increased number of reported failures with the present material of squeezing cylinder, it has been proposed that En 19 steel should be used as an alternate material and its analysis has been done to check its performance. The chemical composition and mechanical properties of En19 steel are listed below in table 6 and 7 respectively.

Table 6: Chemical Composition of En19 Steel

\begin{tabular}{|c|c|}
\hline Chemical & Composite (Weight \%) \\
\hline $\mathrm{C}$ & 0.45 \\
\hline $\mathrm{Mn}$ & 0.80 \\
\hline $\mathrm{Cr}$ & 1.50 \\
\hline $\mathrm{Mo}$ & 0.40 \\
\hline $\mathrm{Si}$ & 0.35 \\
\hline $\mathrm{S}$ & 0.05 \\
\hline $\mathrm{P}$ & 0.035 \\
\hline
\end{tabular}

Table 7: Mechanical Properties of En19 Steel

\begin{tabular}{|c|c|c|c|c|}
\hline Density & Tensile Strength Ultimate & Tensile Strength Yield & Modulus of Elasticity & Poisson's Ratio \\
\hline $7.80 \mathrm{~g} / \mathrm{cm}^{3}$ & $655 \mathrm{MPa}$ & $415 \mathrm{MPa}$ & $210 \mathrm{GPa}$ & 0.30 \\
\hline
\end{tabular}

The property of both mild steel and En19 steel were added in the material library of ANSYS and a detailed analysis has been carried out for the following parameters: total deformation, stresses produced, structural error, strain energy etc.

\section{RESULTS AND DISCUSSIONS}

The squeezing cylinder fails because of internal leakage. This leakage is caused when the circular profile of inner diameter of cylinder changes to oval shape due to continuous wear by the loading and vibrations in the machine. It has been observed that this internal leakage initiates at that position in a squeezing cylinder where the piston stands for the maximum time. This region lies near the neck of cylinder. The figure 4 below shows that the maximum deformation and stress concentration lies around the neck area and hence the leakage initiates at this position. 


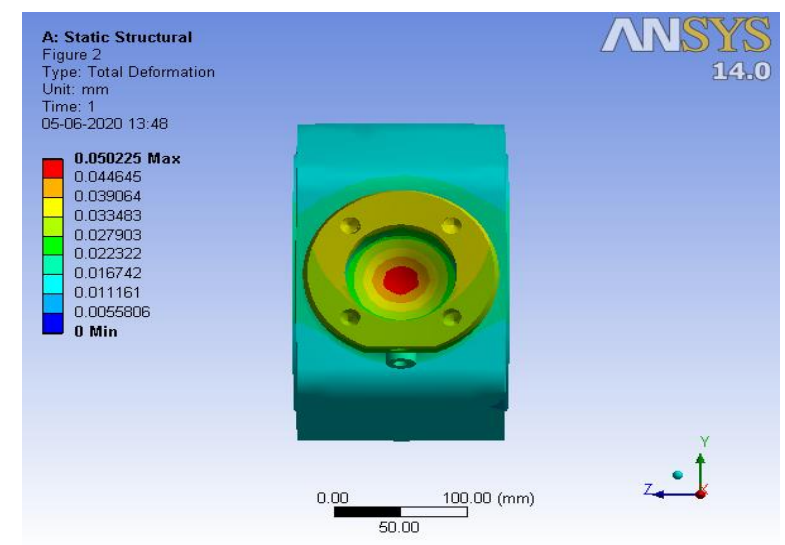

Figure 4: Total Deformation in Squeezing Cylinder.

\section{A: Comparison of Total Deformation}

Based on the ANSYS analysis, the total deformation for both the materials of the squeezing cylinder is shown in figure 5. It is observed from figure 5 that when the machine is working and a pressure of $13 \mathrm{MPa}$ is applied inside the squeezing cylinder, the total deformation in En19 steel squeezing cylinder is less than the IS2062 mild steel cylinder. Total deformation is used to obtain displacements from stresses. In total deformation, it gives a square root of the summation of the square of $\mathrm{x}$-direction, $\mathrm{y}$-direction and z-direction.

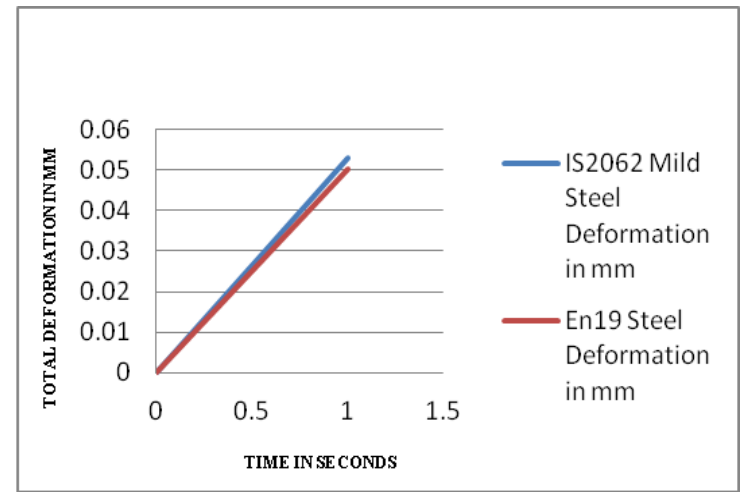

Figure 5: Total Deformation in En19 and IS2062 Mild Steel Squeezing Cylinders.

Figure 6 shows the maximum deformation for En19 cylinder is $0.050225 \mathrm{~mm}$ and that for IS2062 mild steel cylinder is $0.052876 \mathrm{~mm}$.

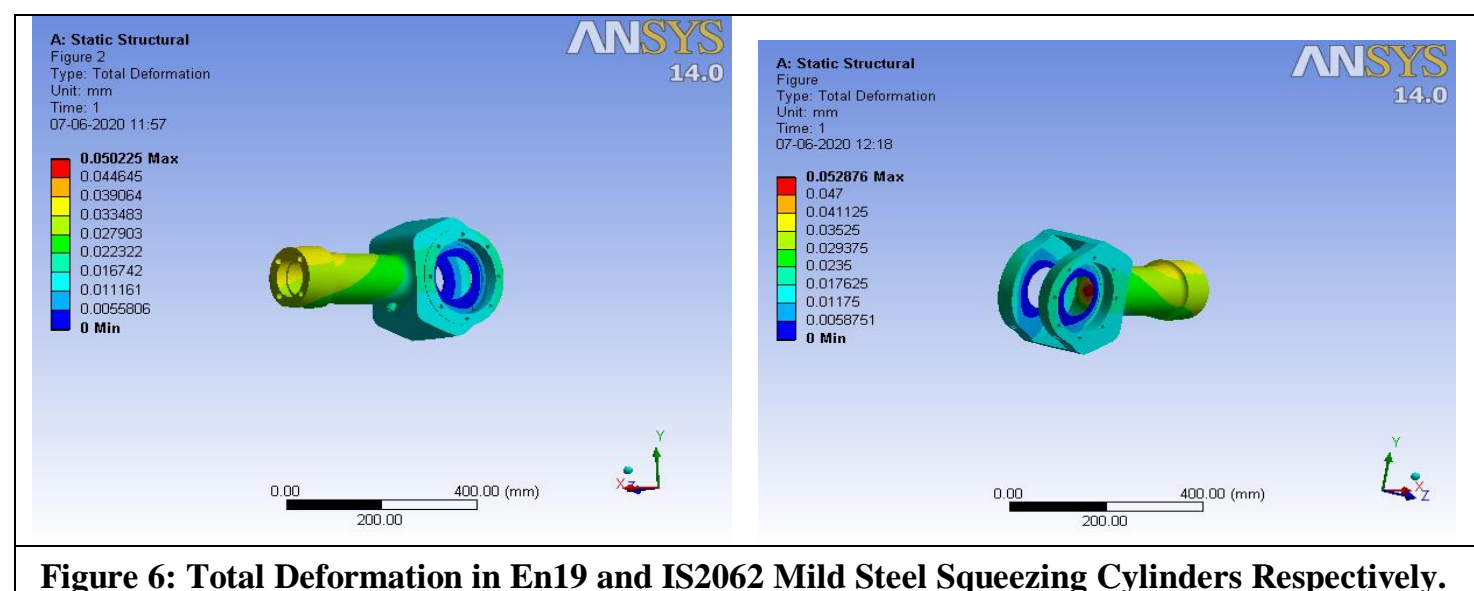




\section{B: Comparison on the Basis of Equivalent Stress}

On computing the equivalent stress, the maximum stress produced in En19 steel cylinder is 176.97 MPa whose tensile yield strength is $415 \mathrm{MPa}$. Thus having a factor of safety of 2.35. The area where stress concentration is maximum lies near the neck region. While the maximum value of stress produced in IS2062 mild steel cylinder is $179.33 \mathrm{MPa}$ for which the tensile yield strength is $250 \mathrm{MPa}$ giving a factor of safety of 1.40 .
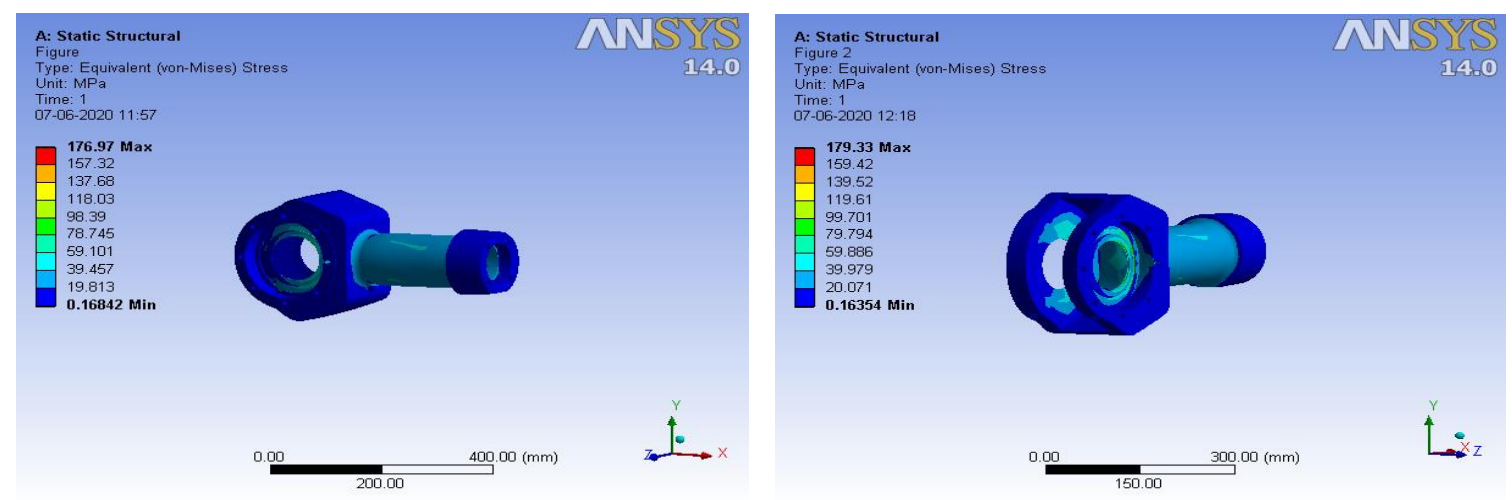

Figure 7: Equivalent Stress Distribution in En19 and IS2062 Mild Steel Squeezing Cylinders.

That is the reason that the squeezing cylinders made by IS2062 mild steel fails earlier leading to reduced efficiency and work life of tamping machine. Fig. 7 shows the distribution of equivalent stress distribution in En19 and IS2062 mild steel squeezing cylinders respectively.

\section{C: Comparison on the Basis of Normal and Principal Stresses}

The table 8 shows that when a working pressure of $13 \mathrm{MPa}$ is applied within the squeezing cylinder, the maximum values of normal stresses and principal stresses ranges from $105 \mathrm{MPa}$ to $116 \mathrm{MPa}$ for both the materials but the important point is that the yield strength for IS2062 mild steel is $250 \mathrm{MPa}$ and that of En19 it is $415 \mathrm{MPa}$. Therefore, it can be concluded that under repeated loading and vibrations En19 steel will give better performance.

Table 8: Maximum Value of Stresses Developed when a Pressure of 13 MPa is Applied

\begin{tabular}{|l|c|c|c|c|}
\hline \multicolumn{1}{|c|}{ Material } & $\begin{array}{c}\text { Normal } \\
\text { Stress } \\
\text { (x-axis) in } \\
\text { MPa }\end{array}$ & $\begin{array}{c}\text { Max. Principal } \\
\text { Stress } \\
\text { in MPa }\end{array}$ & $\begin{array}{c}\text { Tensile Yield Strength in } \\
\text { MPa }\end{array}$ & $\begin{array}{c}\text { Ultimate Tensile Strength in } \\
\text { MPa }\end{array}$ \\
\hline $\begin{array}{l}\text { IS2062 Mild } \\
\text { Steel }\end{array}$ & 105.77 & 113.34 & 250 & 410 \\
\hline En19 Steel & 108.67 & 116.08 & 415 & 655 \\
\hline
\end{tabular}

\section{D: Comparison on the Basis of Equivalent Elastic Strain}

When the squeezing cylinders are filled with working fluid and pressure is applied on the cylinder walls, the maximum strain is spotted near area which are fixed on the eccentric shaft and also near the neck area where the leakage was first detected. 

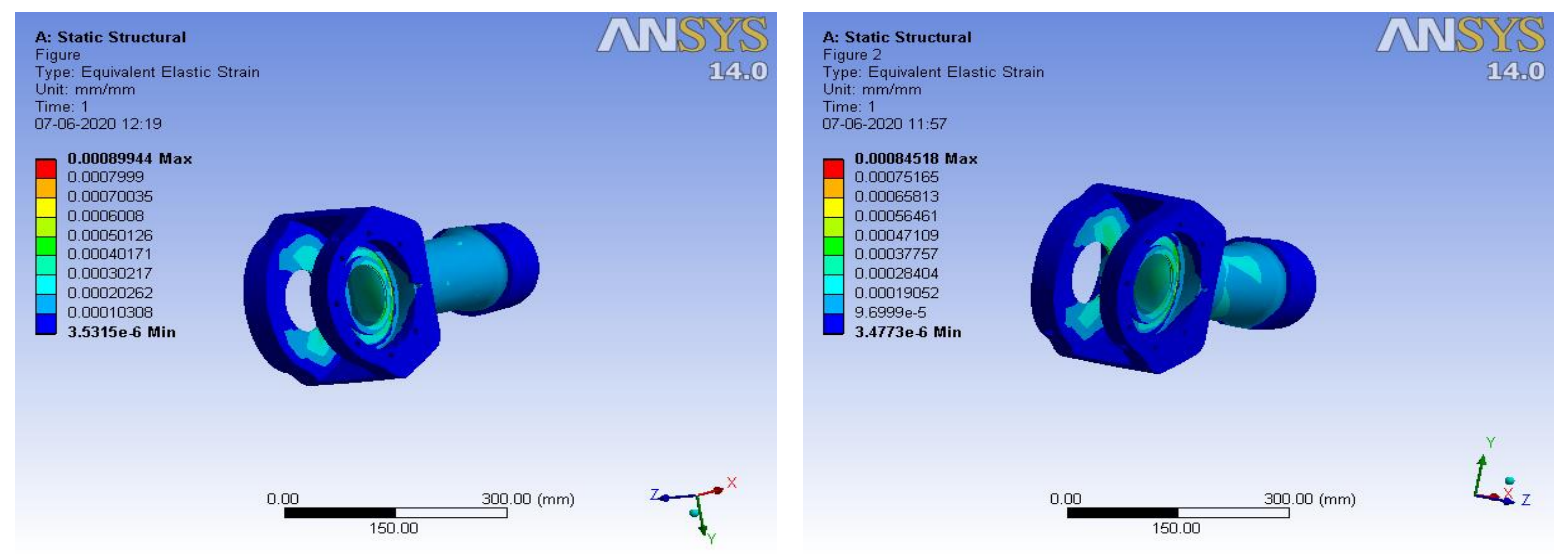

Figure 8: Equivalent Elastic Strain Distribution in En19 and IS2062 Mild Steel Squeezing Cylinders.

The comparative analysis shows that the maximum strain produced in En 19 steel cylinder is $8.4 \mathrm{X} 10^{-4}$ whereas in IS2062 mild steel squeezing cylinder, the maximum values is slightly higher $\left(=8.9944 \times 10^{-4}\right)$. Hence En19 steel shows better results.

With the help of the values obtained of equivalent stress and strain for both the materials, a stress strain curve has been plotted in figure 9. The graph shows that the stresses and strain developed in IS2062 mild steel are towards the higher side as compared to En19 Steel. But the important point is that that stresses developed in IS2062 mild steel is around 180 $\mathrm{MPa}$ and the yield strength of it is $250 \mathrm{MPa}$ it is because of this reason under repeated loading and a continuous vibration the IS2062 mild steel cylinders fails early. The proposed material En19 has a yield strength of $415 \mathrm{MPa}$ which is nearly double the stresses being developed in the cylinder when it is in working condition and therefore it has a better factor of safety.

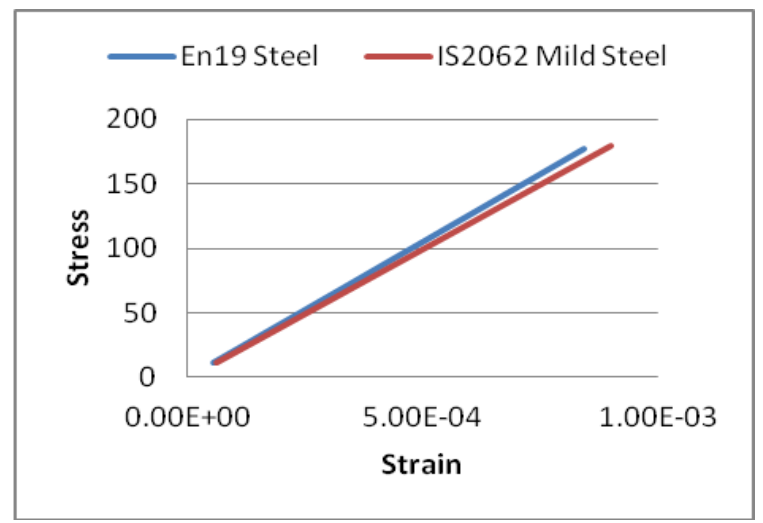

Figure 9: Stress Vs Strain for En19 Steel and IS2062 Mild Steel.

\section{E: Comparison on the Basis of Structural Error}

Structural energy error is the measure of the discontinuity of the stress field. The structural energy error distribution shown in figure 10 depicts that the structural energy error are seen more in IS2062 mild steel cylinder than En19 steel cylinder. Now when there are more stress discontinuity that means the chances of failure is more. The structural error distribution shows that it is concentrated near the neck of cylinder and it has also been reported in various failure analysis reports of $\mathrm{CPOH}$, Prayagraj that leakage in cylinders start at the position where pistons stands for maximum time, which is the neck region. Therefore, it is suggested that En19 steel should be used to manufacture squeezing cylinders as it shows less structural error. 

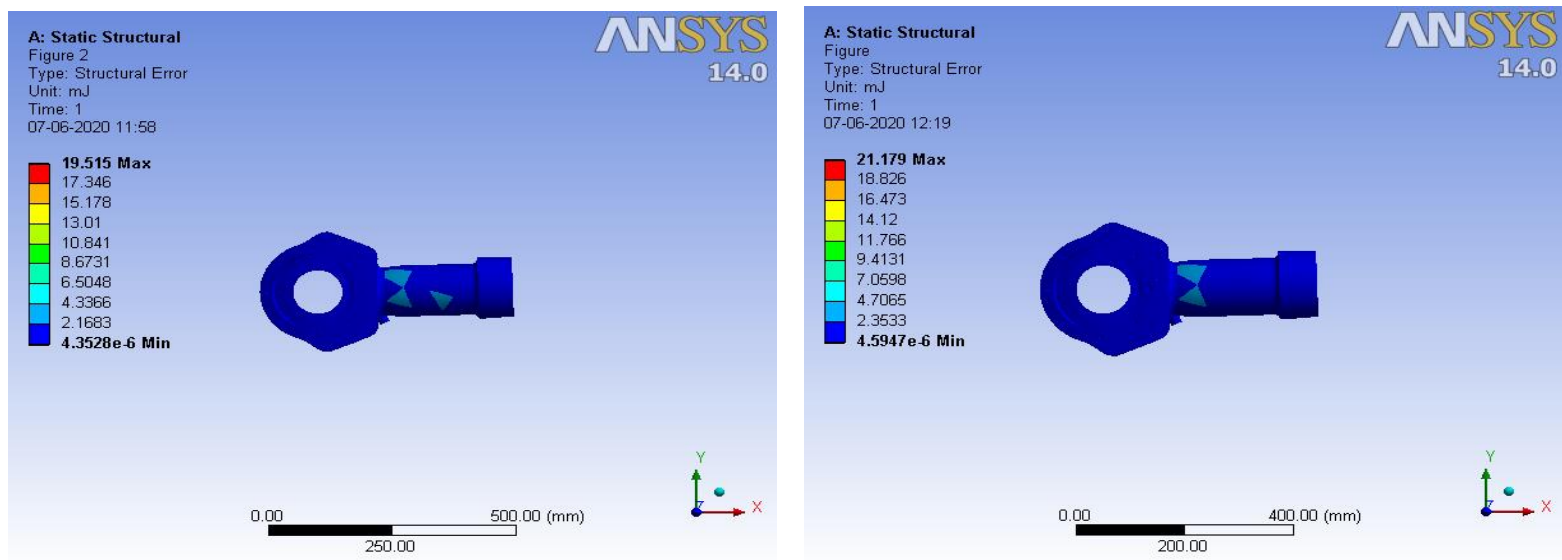

Figure 10: Structural Error Distribution in En19 and IS2062 Mild Steel Squeezing Cylinders.

\section{CONCLUSIONS}

The above analysis and comparative study clearly shows that En19 steel performs better than IS2062 mild steel and will improve the quality of squeezing cylinder thus enhancing the life of tamping unit. Though on fast moving machines few failures during stabilization period can't be eliminated completely but it is expected that implementation of the results will definitely reduce the frequency of failure.

\section{FUTURE SCOPE}

The proposed material En19 steel gives better results. Other alternative materials like En9, En24, En24T etc can also be analyzed and compared.

\section{REFERENCES}

1. Handbook for Track Maintenance. Indian Railway Institute for Civil Engineering, Pune, May, 2016.

2. S. Kaewunruen, and AM. Remennikov, "Effect Of Improper Ballast Packing/Tamping on Dynamic Behaviors Of On-Track railway Concrete Sleeper", International Journal of Structural Stability and Dynamics, Vol. 7, no. 1, pp. 167-177, 2007.

3. A. M. Remennikov and S. Kaewunruen. "A review of loading conditions for railway track structures due to train and track vertical interaction” Progress Struct. Engg. Mater (2006).

4. G. Saussine, E. Azéma, R. Perales, and F. Radjaï. "Compaction of Railway Ballast During Tamping Process: A Parametric Study”, AIP Conference Proceedings, 1145, 469 (2009).

5. Chavan, Amrita B., and K. Rajeswari. "The design and developement of decentralized digilocker using blockchain." International Journal of Computer Science Engineering and Information Technology Research (IJCSEITR) 9 (2019): 29-36

6. K. Meshram, P. Awachat. "Design of Advance Compacting Tool for Railway Track: A Review." International Journal for Scientific Research \& Development.Vol. 6, Issue 01, ISSN (online): 2321-0613, 2018.

7. C.W. Tan, G.I. Webb, F. Petitjean, and P. Reichl, "Machine learning approaches for tamping effectiveness prediction", www.researchgate.net / publication / 317662829.

8. R. Santos, and P.F. Teixeira, "Heuristic Analysis of the Effective Range of a Track Tamping Machine." Journal of 
Infrastructure Systems, pp. 314-322, 2012.

9. C. Min, G. Gong, and Y. Liu, "Design and Simulation Research on New Tamper Based on ADAMS." International Conference on Digital Manufacturing \& Automation, 978-0-7695-4286-7/10, 2010 IEEE.

10. Literature supplied by M/s. Plasser India with various Tamping and Stabilization machines.

11. Kaur, H. A. R. P. R. E. E. T., J. A. S. P. A. L. Singh, and SATINDER KAUR Khattra. "The workability and compressive strength of concrete using textile mill sludge and plasticizer." I Jl Civil, Structural, Environl Infrastructure Eng Research Dev 7 (2017): $1-8$.

12. Mechanized Tamping \& Stabilization. Indian Railways Institute of Civil Engineering, Pune, November, 2016.

13. Report No.24 of 2015 (Railways) Volume II.

14. Research Design and Standards Organisation Manaknagar, Lucknow. List of specification and Drawing. December, 2019.

15. Post POH analysis of failures in tamping units from 01.04.2018 to 31.12.2018 by CPOH workshop Allahabad.

16. Prakash, D. Surrya, et al. "A review on latest development of aluminium alloy metal matrix composite through powder metallurgy route." International Journal of Mechanical and Production Engineering Research and Development 2018: $235-241$.

17. A.K. Gupta, D.M. Jesudas, P.K. Das, and K. Basu, "Performance Evaluation of Different Types of Steel for Duck Foot Sweep Application.” Biosystems Engineering, Vol 88 (1), pp. 63-74, 2004.

18. R.J. Rider, S.J. Harvey, and H.D. Chandler, “Fatigue and Ratcheting Interactions. ” International Journal Fatigue, Vol 17, no. 7, pp. 507-5011,1995.

19. Indian Railway Track Machine Manual, 2000.

20. Indian Railway Permanent way Manual, 2004.

21. Modern Railway Track, 2nd edition, by Coearaad Esveld.

22. Understanding Track Engineering (2014) published by Permanent Way Institution.

23. Track Compendium, 2nd edition, by Dr. Bernhard Lichtberger.

24. Sharma, Aman Kumar, Anita Ganpati, and Anju Bala. "Cloud Computing: A data Security Framework." International Journal of Computer Science Engineering and Information Technology 3.5.

25. G. Kumaran, D. Menon and K. K. Nair. “Dynamic studies of railtrack sleepers in a track structure system.” J Sound Vib 268 (2003) 485-501. 


\section{AUTHORS PROFILE}

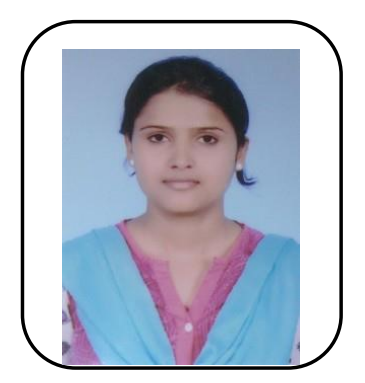

Shruti Singh Persuing Master of Engineering in Manufacturing Technology from National Institute of Technical Teachers Training and Reseacrch, Chandigarh. B.Tech from Dr. APJ Abdul Kalam Technical University Prayagraj. Area of Research Design, Material Science, Machining and Manufacturing Technology.

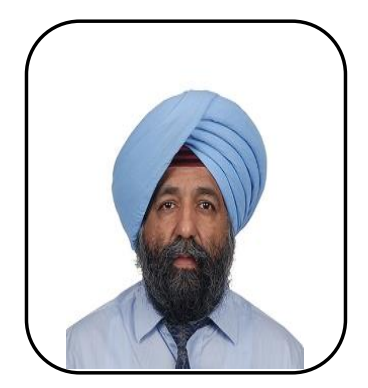

Dr. S.S. Banwait Professor in Department of Mechanical Engineering at National Institute of Technical Teachers Training and Research, Chandigarh. Ph.D.(Mechanical Engineering) from Thapar University. M.Tech.(Mechanical Engineering) from IIT Delhi. B.E.(Mechanical Engineering) from Rani Durgavati University Jabalpur. Research Interests: Engineering Design, Production management, Manufacturing Technology, Conventional Machining. 